\title{
Program of care for cancer patients in health insurance in Brazil: an overview
}

\begin{abstract}
Due to the change in its demographic profile, Brazil presents an increase in the incidence and prevalence of Non-Degenerative Chronic Diseases. Among these, the cancer deserves a prominence, since it requires of the health system different therapeutic and care actions. In order to help care for cancer patients, it is offered in São Paulo, Brazil, by two health insurance companies for two years, a program in which the sick are followed up with a multidisciplinary team, who attend at home and through a central phone. This assistance model promotes health education actions and continued assistance, including plaid care, actions that, together, offer an integral and humanized care for coping with this disease.
\end{abstract}

Keywords: cancer, health, treatment, care, life quality

\author{
Volume 2 Issue I - 2018 \\ Maria Elisa Gonzalez Manso,' Leandro Tadeu \\ Prazeres Maresti, ${ }^{2}$ Thiago Henrique Belchior \\ França, ${ }^{2}$ Vanessa Tiemi Comosako ${ }^{3}$ \\ 'Social Gerontology Program, Universidade Católica de São \\ Paulo, Brazill \\ ${ }^{2}$ Nursing graduation program, UNIP, Brazil \\ ${ }^{3}$ Faculdade das Américas, Brazil
}

\begin{abstract}
Correspondence: Maria Elisa G Manso, Social Gerontology Program - PUC SP, R Celso de A Marques n740 Mooca, São Paulo, Brazil, Tel +55-I I-99365263।,

Email mansomeg@hotmail.com
\end{abstract}

Received: September 20, 2017 | Published: January 02, 2018

\section{Introduction}

Cancer is the result of a disordered and uncontrolled growth of cells with great invasive potential. Its development requires multiple steps that occur over the years. It is a multifactorial disease, and within its determinants, the main risk factors are: obesity, reduced intake of fruits and vegetables, sedentary lifestyle, smoking and alcohol.

Brazil is undergoing changes in its demographic profile, with a significant increase in the number of elderly people in the population, as a consequence of the process of urbanization, industrialization and advances in science and technology. This transition, associated to the new lifestyles, has modified the pattern of illness of the Brazilian population, greatly increasing the incidence and prevalence of chronic non-communicable diseases, among them, cancer. ${ }^{1}$ This increase in the number of cases makes cancer a public health problem for the country, whose control and prevention must be prioritized. Among the care offered to patients with this disease, palliative care deserves special mention, as it promotes the prevention and relief of suffering and offers a biopsychosocial and spiritual support to the patient and his relatives. To meet all the dimensions in which the individual is inserted, this service requires the training of a multidisciplinary team, so that a link can be established capable of offering a humanized support. In this way, the prolongation of life with quality and care is offered. $^{1}$

\section{Discussion}

The Brazilian health system is characterized by dual care: on the one hand, a free and universal public system (called the single health system) and, on the other hand, a supplementary system of access for payment (called supplementary). The payment of health insurance in Brazil may occur through the direct expenditure of families (individual or family plans) or payment by companies (active and/or retired employees). It is a system that today covers health problems for approximately 40 million people and has been characterized by the implementation of several programs for the prevention of diseases and differentiated care for patients with chronic diseases. ${ }^{2}$
Two of these companies that sell health insurance in Brazil, located in the city of São Paulo, offer their associates who lives in this town, a program aimed at the care of cancer patients, which complements their medical treatment. This is an optional program, free of charge, implemented since 2015, in which the patients are accompanied by a multiprofessional team composed of doctors, nurses, psychologists, social workers, nutritionists and physiotherapists, who attend them at home according to their needs. There is also an uninterrupted (24 hours, 7 days a week) central office where trained nurses, in addition to regularly monitoring and guiding these patients, at intervals between visits, are available to those enrolled in the program and where they can call to heal questions about their treatment (s) or complications.

It is a program based on the construct care line, where the neoplasia patient inserts after having his/her health problem diagnosed and having started his/her proposed treatment. Thus, health education actions and support to fight against the disease are triggered and monitored. When the patient is out of therapeutic possibility, the line of care continues with the offer of palliation, performed in the home of the sick person and by a team specialized in this type of care.

Today, the program serves a total of 1,746 patients, being considered one of the largest programs of this kind in the city of São Paulo. Of the total number of patients, 758 are in remission phase and 988 are in active treatment. For the remission patients, health education and prevention actions are offered. For the others, in addition to the described actions, if they are out of therapeutic possibility, there is the offer of palliation at home. There are currently, in palliative care, 88 patients.

Almost all of the people served by the program have a diagnosis of breast, prostate, colon; lung, endometrial, bladder, lymph nodes, kidney and ovary cancer in descending order of cases, and most of them are over 65 years of age. As already mentioned, all are residents of the city of São Paulo, southeastern region of Brazil, and in this city they carry out their treatment. All are linked to only two health insurance companies and are referred to the program by the doctors who attend them. As mentioned, the program has been in progress 
since 2015. A survey of satisfaction with a sample of these users, between July 20 and 24, 2017, by an independent research institute, found that $75 \%$ of the respondents associate their participation in the program with improvement in their quality of life, $49 \%$ considered the program good and $45 \%$, great. Three recorded testimonies (with the patient's authorization and on condition of anonymity) are reproduced below:

i. Patient in remission: "I am very pleased because both the nurses and the nurses who always call me, they call with great constancy and are very interested in knowing how I am living with this cancer problem, they clarify me, I only have who compliment, I am very satisfied "

ii. Patient on treatment: "I often ask the doctor something, but he gives priority to something else, and then when the nurse calls me, I ask questions and she clarifies me."

iii. Family member of palliative care patient: "I can only speak well of the program, we had a spectacular assistance, both my husband and the family in general, so, really, I can only speak well."

\section{Conclusion}

The research demonstrated not only patient satisfaction, but the achievement of the program's objectives in all its line of care, from treatment to palliation, which are: quality of life, humanization and integral care. With the increase in the number of cases of cancers in the population, as well as in other chronic diseases, health care must go through the concern with these three pillars. In this context, health education and palliative care tend to have an increasingly prominent and fundamental dimension.

As a limitation to the implementation of the program, it is noted above all the resistance of doctors and families to accept palliation care for cultural reasons. Recent research ${ }^{3}$ demonstrated that for most Brazilians prolonging life is more important than dying without pain and suffering. Another limitation is the number of people served. Despite being considered one of the largest programs in coverage for cancer patients in the Brazilian supplementary health segment, the number of patients served by the program is still insufficient, considering the number of cases in the city where the program occurs and in the program itself parents.

\section{Acknowledgements}

None.

\section{Conflict of interest}

The author declares no conflicts of interest.

\section{References}

1. Maria Elisa Gonzalez Manso, Ruth G Da Costa Lopes, Anelise Fonseca, et al. Cuidados Paliativos para o portador de câncer. Revista Portal de Divulgação. 2017;52:77-82.

2. http://www.ans.gov.br/anstabnet/cgi-bin/dh?dados/tabnet_tx.def

3. Pesquisa revela o que as pessoas desejam nos últimos anos de vida. Brazil: Springer; 2017. 